Analytical Methods

\title{
RAPD and SCAR markers as potential tools for detection of milk origin in dairy products: Adulterant sheep breeds in Serra da Estrela cheese production
}

\author{
Joana T. Cunha ${ }^{a}$, Tânia I.B. Ribeiro ${ }^{\mathrm{b}}$, João B. Rocha ${ }^{\mathrm{b}}$, João Nunes ${ }^{\mathrm{b}}$, José A. Teixeira ${ }^{\mathrm{a}}$, Lucília Domingues ${ }^{\mathrm{a}, *}$ \\ ${ }^{a}$ CEB - Centre of Biological Engineering, University of Minho, 4710-057 Braga, Portugal

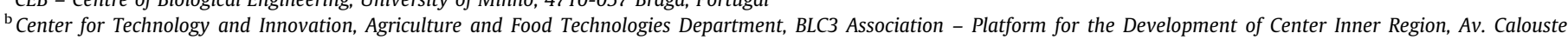 \\ Gulbenkian $n^{\circ} 71$ Zona Industrial, 3400-060 Oliveira do Hospital, Portugal
}

\section{A R T I C L E I N F O}

Article history:

Received 20 November 2015

Received in revised form 10 May 2016

Accepted 16 May 2016

Available online 17 May 2016

\section{Keywords:}

RAPD

SCAR

Ovine breeds

Milk adulteration

Serra da Estrela cheese

Quality control

\begin{abstract}
A B S T R A C T
Serra da Estrela Protected Designation of Origin (PDO) cheese is the most famous Portuguese cheese and has a high commercial value. However, the adulteration of production with cheaper/lower-quality milks from non-autochthones ovine breeds compromises the quality of the final product and undervalues the original PDO cheese. A Randomly Amplified Polymorphic DNA (RAPD) method was developed for efficient detection of adulterant breeds in milk mixtures used for fraudulent production of this cheese. Furthermore, Sequence Characterized Amplified Region (SCAR) markers were designed envisioning the detection of milk adulteration in processed dairy foods. The RAPD-SCAR technique is here described, for the first time, to be potentially useful for detection of milk origin in dairy products. In this sense, our findings will play an important role on the valorization of Serra da Estrela cheese, as well as on other high-quality dairy products prone to adulteration, contributing to the further development of the dairy industry.
\end{abstract}

(c) 2016 Elsevier Ltd. All rights reserved.

\section{Introduction}

Food safety and quality are nowadays a major concern. Consequently, the improvement and establishment of authentication processes are receiving growing attention (Borràs et al., 2015; Fontanesi, 2010; Kamal \& Karoui, 2015; Kumar et al., 2015; Loutfi, Coradeschi, Mani, Shankar, \& Rayappan, 2015; Sentandreu \& Sentandreu, 2014) mainly concerning superior-quality products that, due to its elevated economic value, are more prone to fraudulent activities, which severely affect the agro-food industry and market.

Serra da Estrela cheese is a Protected Designation of Origin (PDO) cheese and is perceived as a unique high-quality food product. It is legitimately manufactured from raw milk of the autochthonous sheep breed Serra da Estrela; however, mixture of original milk with cheaper and/or low quality milk from other more productive breeds is a common practice that may result in devaluation of the original cheese. Being the most famous Por-

\footnotetext{
* Corresponding author.

E-mail addresses: jcunha@ceb.uminho.pt (J.T. Cunha), tania.ribeiro@blc3.pt (T.I. B. Ribeiro), joao.bernardo@blc3.pt (J.B. Rocha), joao.nunes@blc3.pt (J. Nunes), jateixeira@deb.uminho.pt (J.A. Teixeira), luciliad@deb.uminho.pt (L. Domingues).
}

tuguese cheese (Reis \& Malcata, 2011), these adulterations may lead to serious problems at both social and economic levels. These drawbacks, allied to an absence of methods for breed identification on this cheese, create an urgent necessity for robust and reliable analytical techniques that efficiently allow detection of the breed origin of milk in Serra da Estrela PDO cheese.

The discovery that the somatic cells present in milk may be used as source of DNA (Lipkin, Shalom, Khatib, Soller, \& Friedmann, 1993), led to the development of several PCR-based techniques to allow milk origin identification in dairy products, such as Restriction Fragment Length Polymorphism (RFLP) (Abdel-Rahman \& Ahmed, 2007; Fontanesi, Beretti, Dall'Olio, Portolano, Matassino \& Russo, 2011), multiplex (Agrimonti, Pirondini, Marmiroli, \& Marmiroli, 2015; Bottero et al., 2003; Gonçalves, Pereira, Amorim, \& van Asch, 2012) and Real Time PCR (Agrimonti et al., 2015; Ganopoulos, Sakaridis, Argiriou, Madesis, \& Tsaftaris, 2013; López-Calleja et al., 2007). Despite the fact that these techniques have been successfully reported for identification of milk source, the differentiation of milk origin at an intra-species level is still a major challenge (Choy, Oh, \& Kang, 2001; Cirillo et al., 2012; Fontanesi, Beretti, Dall'Olio, Portolano, Matassino, \& Russo, 2011; Sardina et al., 2015). Furthermore the lack of genetic information of Portuguese ovine breeds poses as a 
major obstacle, creating the necessity for more sensitive strategies, directly focused at the Serra da Estrela PDO cheese industry.

Taking this into account, in this work we aimed at the development of an efficient Random Amplified Polymorphic DNA (RAPD) technique for identification of adulterant breeds in milk mixtures used for fraudulent Serra da Estrela PDO cheese production. Additionally, we envisioned the design of robust breed-specific Sequence Characterized Amplified Regions (SCAR) markers to facilitate the origin of milk determination in this product.

\section{Materials and methods}

\subsection{Milk samples and DNA extraction}

Four sheep breeds were studied in this work: the autochthonous Serra da Estrela breed, the Portuguese breed Churra do Minho and two breeds, present in Serra da Estrela region, with superior milk productivity and putatively used for adulteration of Serra da Estrela cheese: Assaf, original from Israel; and a crusade of different pollet breeds (Mocha). Milk samples from these breeds were provided by Paulo Rogério Simões Figueiredo, Lda. Genomic DNA was extracted from milk following the protocol described by (López-Calleja et al., 2005) with modifications (Fig. 1). Briefly, the somatic cells were obtained from the milk sample by mixing with a clearing solution (0.25 M EDTA, pH 8.0, 0.5\% Triton X-100) followed by centrifugation. The cell pellet was incubated overnight in extraction buffer ( $10 \mathrm{~mm}$ Tris- $\mathrm{HCl}, \mathrm{pH} 7.5,150 \mathrm{~mm} \mathrm{NaCl}$,
2 mm EDTA, pH 8.0, and 1\% SDS), guanidine hydrochloride, and proteinase K (BIORON). The extraction was performed with Phenol stabilized:Chloroform:Isoamyl Alcohol 25:24:1 (PanReac AppliChem) and the DNA was precipitated from the supernatant with chilled absolute ethanol. The concentration and purity of the total DNA were spectrometrically determined $\left(A_{260 / 280}\right.$ and $\left.A_{260 / 230}\right)$ using a NanoDrop 1000 (Thermo Scientific).

\subsection{RAPD analysis}

The RAPD reaction was performed in $50 \mu \mathrm{l}$ reaction mixes consisting of $200 \mathrm{ng}$ of genomic DNA, $4 \mathrm{mM} \mathrm{MgCl}, 1 \mu \mathrm{M}$ of primer (NZYTech), $0.5 \mathrm{mM}$ dNTP mix, 5\% (v/v) dimethyl sulfoxide (DMSO, Roche), NZYTaq buffer and $2.5 \mathrm{U}$ of NZYTaq (NZYTech). The amplification was performed in a Piko ${ }^{\mathrm{TM}}$ Thermal Cycler (ThermoScientific) as follows: $95^{\circ} \mathrm{C}$ for $2 \mathrm{~min}, 45$ cycles of $95^{\circ} \mathrm{C}$ for $1 \mathrm{~min}$, annealing at $34^{\circ} \mathrm{C}$ for $1 \mathrm{~min}$ and extension at $72{ }^{\circ} \mathrm{C}$ for $2 \mathrm{~min}$, followed by a final extension step of $72{ }^{\circ} \mathrm{C}$ for $5 \mathrm{~min}$. The amplification products were loaded on $1.5 \%$ agarose gel in Tris-borateEDTA (TBE) and run in the same buffer for $2.5 \mathrm{~h}$ at $100 \mathrm{~V}$.

\subsection{Cloning and sequencing of adulterant-specific fragment}

The adulterant-specific fragment was excised from the agarose gel, purified using the QIAquick Gel Extraction Kit (QIAGEN) and cloned into pGEM-T Easy vector (PROMEGA), according to the supplier's instructions. The transformed bacterial colonies (NZY5alpha

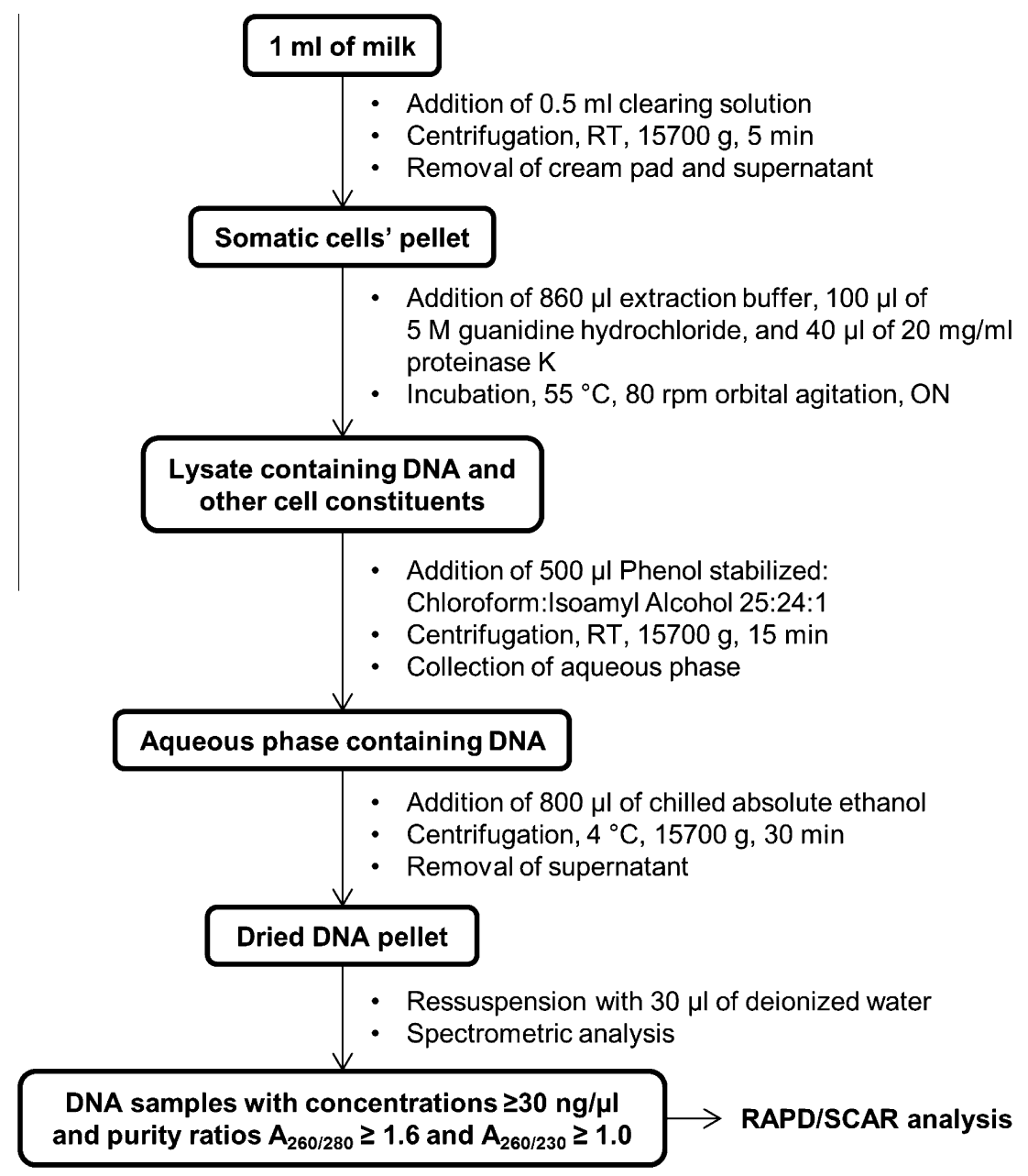

Fig. 1. Schematic representation of the DNA extraction and analysis from milk samples. RT: room temperature. ON: overnight. 
Competent Cells, NZYTech) were screened through colony PCR and 5 clones carrying the expected insert were sequenced (GATC Biotech). Database searches of sequences homology were performed using Blast program (http://blast.ncbi.nlm.nih.gov/Blast.cgi).

\subsection{SCAR design and analysis}

SCAR primers were designed for stringent conditions of size (17-28 bp), GC (Guanine-Cytosine) percentage (40-60\%) and melting temperature $\left(52-62{ }^{\circ} \mathrm{C}\right.$, and less than $5{ }^{\circ} \mathrm{C}$ of difference within primer pair). Amplification with the Crusade-specific primers was

Table 1

RAPD primers and putative adulterant-specific bands. The fragments listed (charac terized by molecular weight in bp) were present in the RAPD profiles of the adulterants Churra do Minho, Assaf or Crusade, and absent in the profiles obtained from Serra da Estrela breed.

\begin{tabular}{lllll}
\hline Primer & Sequence $\left(5^{\prime} \rightarrow 3^{\prime}\right)$ & Churra do Minho & Assaf & Crusade \\
\hline OPB-03 & CATCCCCCTG & - & - & - \\
OPB-07 & GGTGACGCAG & 1000 & 600,1000 & 1000 \\
OPB-10 & CTGCTGGGAC & - & - & - \\
OPB-11 & GTAGACCCGT & - & - & - \\
OPB-12 & CCTTGACGCA & 550,850 & 550,850 & $400,550,850$ \\
GLA-19 & CAAACGTCCGG & $400,900,2000$ & 400 & 350,400 \\
GLB-20 & GCACCCTTAC & 850 & 850 & 750,850 \\
GLC-11 & AAAGCTGCGG & - & - & - \\
GLC-14 & TGCGTGCTTG & - & - & - \\
GLC-15 & GACGGATCAG & - & - & - \\
GLC-20 & ACTTCGCCAC & - & - & - \\
OPA-06 & GGTCCCTGAC & - & 2000 & - \\
OPA-07 & GAAACGGGTG & 1700 & 1400 & 350 \\
OPA-10 & GTGATCGCAG & - & - & - \\
OPA-15 & TTCCGAACCC & - & - & - \\
OPA-16 & AGCCAGCGAA & - & - & - \\
OPA-17 & GACCGCTTGT & - & - & 800 \\
OPA-18 & AGGTGACCGT & 800,1000 & 800,1000 & 800,1000 \\
OPA-19 & CAAACGTCGG & - & - & - \\
OPA-20 & GTTGCGATCC & - & - & - \\
OPB-01 & GTTTCGCTCC & 800 & - & - \\
OPB-05 & TGCGCCCTTC & - & - & - \\
OPB-08 & GTCCACACGG & - & - & - \\
OPB-17 & AGGGAACGAG & - & - & - \\
OPB-19 & ACCCCCGAAG & 1000 & 1000 & - \\
OPB-20 & GGACCCTTAC & 1600 & - & - \\
\hline & & & - & - \\
\hline
\end{tabular}

performed in $50 \mu \mathrm{l}$ reaction mixes consisting of $100 \mathrm{ng}$ of genomic DNA, $3 \mathrm{mM} \mathrm{MgCl}_{2}, 0.1 \mu \mathrm{M}$ of each primer (NZYTech), $0.5 \mathrm{mM}$ dNTP mix, NZYTaq buffer and $2.5 \mathrm{U}$ of NZYTaq (NZYTech). The construct of pGEM-T Easy vector containing the Crusade-specific fragment (Section 2.3) was used as positive control. The thermocycling program was the same as for RAPD analysis, except for the annealing temperature $\left(63^{\circ} \mathrm{C}\right)$ and extension duration $(20 \mathrm{~s})$. The PCR products were resolved by electrophoresis on $1.5 \%$ agarose gel in TBE for $1 \mathrm{~h}$ at $100 \mathrm{~V}$.

\section{Results and discussion}

\subsection{RAPD analysis}

RAPD analysis has been successfully used in sheep genetic diversity (Kumar et al., 2008; Qasim et al., 2011) and cattle breed differentiation (Choy et al., 2001) studies. In this sense, 26 RAPD primers (Table 1) were selected from these works based on their effectiveness to distinguish breeds. These primers were used to analyze milk samples from Serra da Estrela sheep breed, and from 3 putative adulterants: Churra do Minho, Assaf and Crusade (Table 1 ). The resulting profiles showed that 11 of these primers were capable of producing adulterant-specific patterns (Table 1 ), i.e., containing fragments that are present in the RAPD profiles of the adulterants Churra do Minho, Assaf or Crusade, and absent in the profiles obtained from Serra da Estrela breed.

To achieve an easier and fastest identification of adulterants the primers OPA-07 and GLA-19 were selected for further analysis, as they have resulted in amplifications profiles that distinguish each of the adulterants from the Serra da Estrela breed (Table 1, Figs. 2A and $3 \mathrm{~A}$ ). Amplifications with these two primers have been repeated to check for consistency (Figs. 2B and 3B), as RAPD analysis has been reported to have low repeatability and reproducibility (Cirillo et al., 2012; Ghazi, Benmechernene, Kihal, \& Gurakan, 2013; Khandka, Tuna, Tal, Nejidat, \& Golan-Goldhirsh, 1997). Accordingly, it was observed that some of the presumed adulterant-specific fragments identified in the first analysis (Figs. $2 \mathrm{~A}$ and $3 \mathrm{~A}$ ) were absent/fainter or have lost polymorphism in the second amplification (Figs. $2 \mathrm{~B}$ and $3 \mathrm{~B}$ ). Taking this into account only the polymorphic bands consistently amplified in both RAPD analysis were considered to be useful for breed/adulterant

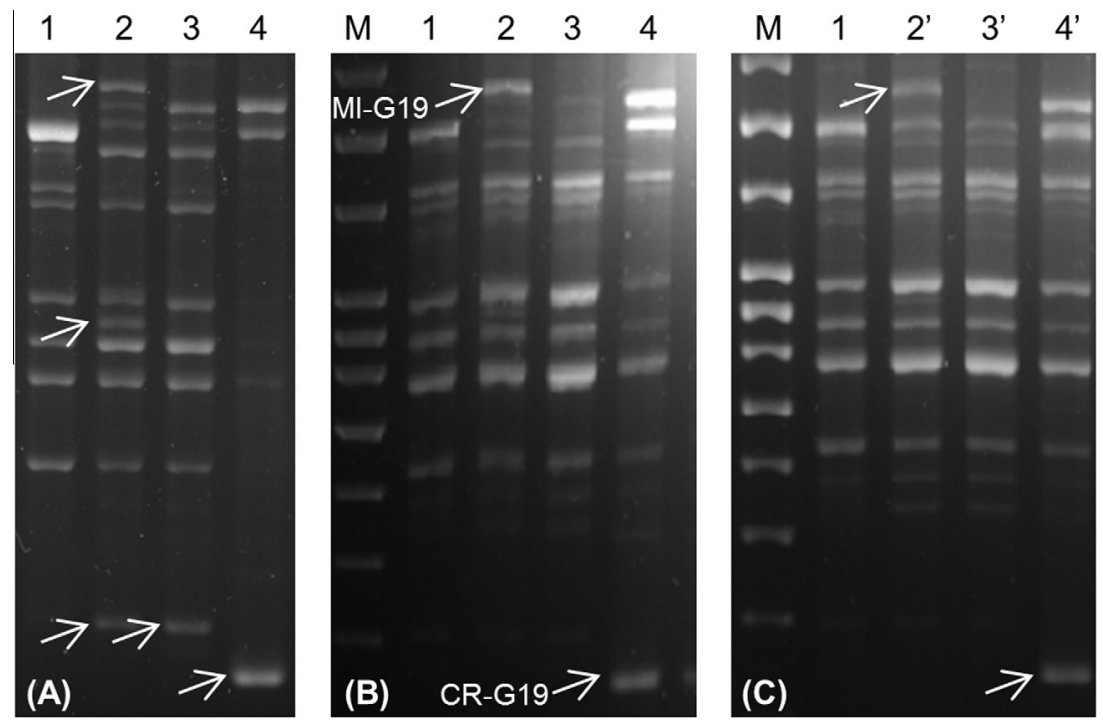

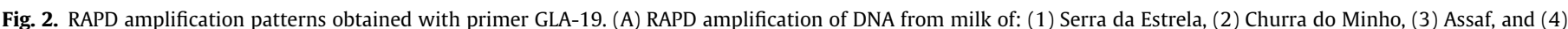

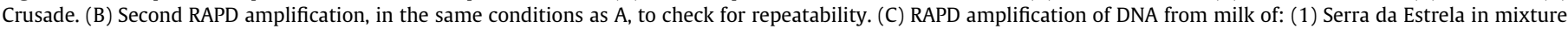
(50\%) with $\left(2^{\prime}\right)$ Churra do Minho, $\left(3^{\prime}\right)$ Assaf, or $\left(4^{\prime}\right)$ Crusade. The polymorphic bands are identified with white arrows. (M) NZYDNA Ladder VII. 

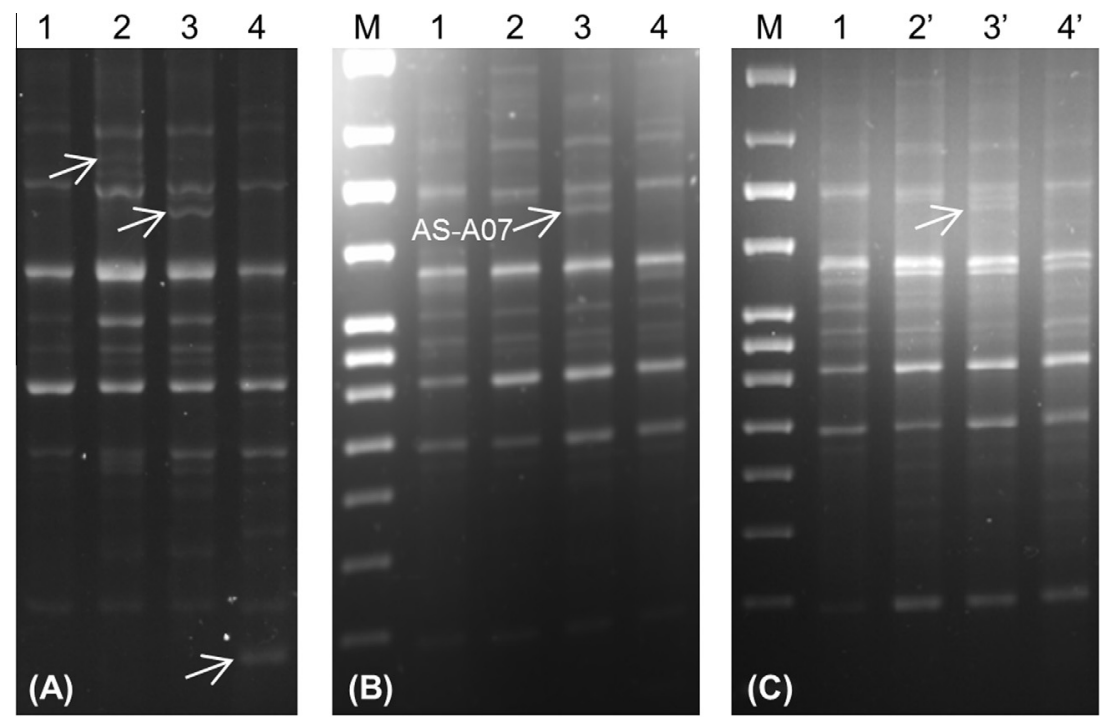

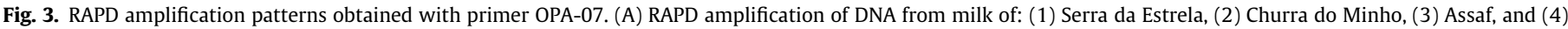

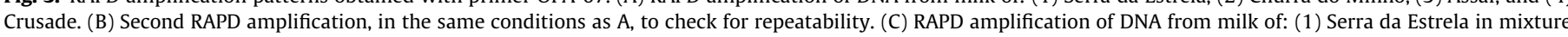
(50\%) with (2') Churra do Minho, (3') Assaf, or (4') Crusade. The polymorphic bands are identified with white arrows. (M) NZYDNA Ladder VII.

identification: the $2000 \mathrm{bp}$ Churra do Minho-specific fragment from GLA-19 (MI-G19, Fig. 2B), the 350 bp Crusade-specific fragment from GLA-19 (CR-G19, Fig. 2B) and the 1400 bp Assafspecific fragment from OPA-07 (AS-A07, Fig. 3B).

As the breed origin of milk has been shown to affect the chemical and sensorial characteristics of cheeses (Ferreira, Pinho, \& Sampaio, 2009) it is unlikely that fraud in Serra da Estrela cheese production occurs with total replacement of the autochthonous milk with that from adulterant breeds. In this sense, it is important to have a molecular technique capable of identifying adulterant milk in mixture with the original milk. To test the efficacy of GLA-19 and OPA-07 primers to detect adulterant milk in the presence of Serra da Estrela sheep's milk, DNA was extracted from mixtures of milk from the original breed with each of the putative adulterants. Fig. $2 \mathrm{C}$ shows that, even in the presence of Serra da Estrela milk, RAPD analysis with primer GLA-19 allows the clear amplification of Minho- and Crusade-specific fragments. However, analysis of these mixtures with the primer OPA-07 have resulted in a less intense and distinguishable Assaf-specific band (Fig. 3C), disqualifying this primer for efficient identification of Assad breed in milk mixtures.
Regardless of the promising results obtained with GLA-19 in inter-breed comparison (Fig. 2), when testing this primer for intra-breed consistency the MI-G19 band was not amplified in all the Churra do Minho individuals analyzed (Fig. 4), showing that this fragment is not representative of this breed. On the other hand, the Crusade-specific band CR-G19 was amplified in all the Crusade individuals tested (Fig. 4). Additionally, this band was absent in all of the non-Crusade individuals (Fig. 4), attesting that the CR-G19 fragment is discriminant of this breed.

In spite of the skepticism over reproducibility in RAPD analysis, several studies have shown that after appropriate optimization of the RAPD protocol, reproducible results may be achieved (Blixt, Knutsson, Borch, \& Rådström, 2003; Güçlü, Aldem, \& Güler, 2004; Perry et al., 2003). In this context, we suggest that an optimized RAPD analysis, when performed in strictly consistent conditions and focused in fragments with satisfactory repeatability, may be a valuable tool for identification of sheep breed in a first stage of milk authentication in dairy industry. Specifically, we establish the primer GLA-19, when used in the RAPD conditions here described, to be useful for the identification of Crusade breed in milk mixtures.

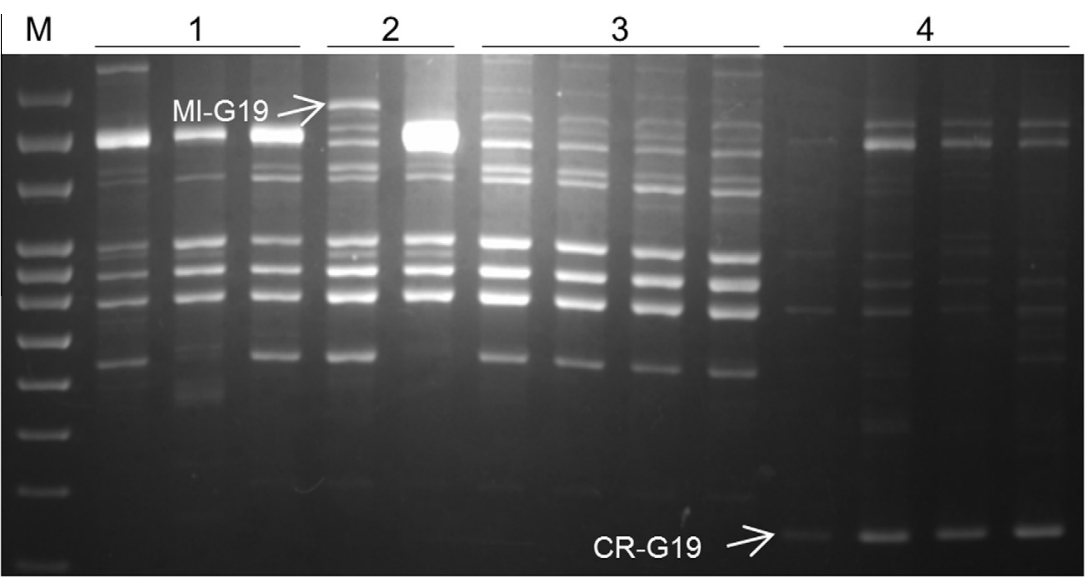

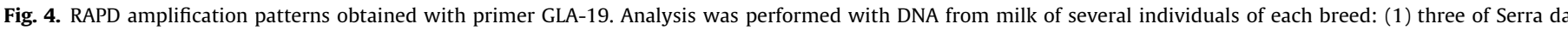
Estrela, (2) two of Churra do Minho, (3) four of Assaf, and (4) four of Crusade. The polymorphic bands are identified with white arrows. (M) NZYDNA Ladder VII. 
M

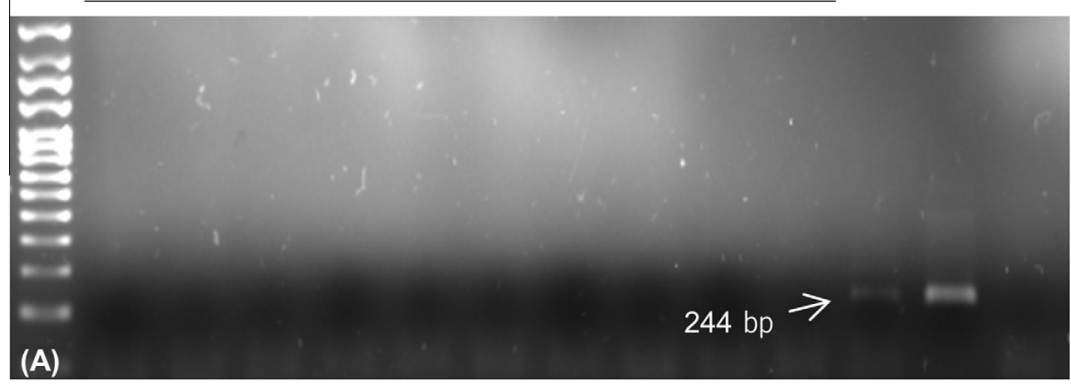

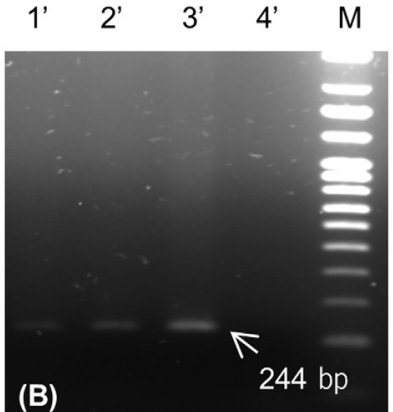

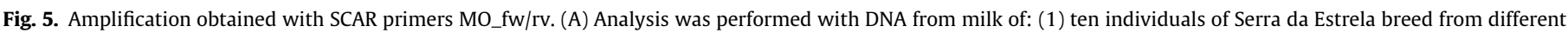

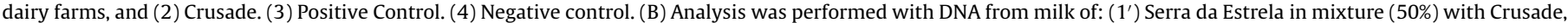
and $\left(2^{\prime}\right)$ Crusade. ( $\left.3^{\prime}\right)$ Positive Control. (4') Negative control. (M) NZYDNA Ladder VII. (M) NZYDNA Ladder VII.

\subsection{SCAR analysis}

Despite the fact that RAPD analysis has shown to be successfully used for breed detection in milk samples, it must be taken into account that the milk processing in dairy industry probably results in degradation of DNA on the final product. In fact, we have observed that, in comparison with cheese, milk has a higher content of nuclear DNA, while mitochondrial DNA is more prevalent in cheeses (Fig. S1 in Supplementary data). This fact indicates that, even though nuclear DNA is still present in cheese, it has been partially degraded in the process of cheese production, while the more stable mitochondrial DNA is less affected. Taking this into account, a more specific technique may be needed for efficient breed identification on final products of dairy industry. In this sense, the Crusade-specific fragment CR-G19, showing no homology with Ovis aries sequences from NCBI database, was used for the design of SCAR primers (CR_fw: CAAACGTCCGGTGGTTTCAAGG and CR_rv: TTACAATACTAAAGGCTGCCGACAG) that, being longer and more specific than RAPD primers, may be suitable for cheese analysis. Moreover, its small predicted amplicon, of $244 \mathrm{bp}$, may offer a further advantage when analyzing products with partially degraded DNA (Chen, Wang, Ge, \& Xu, 2005).

The analysis of DNA from milk of Crusade breed with CR_fw/rv primers yielded a successful PCR amplification (Fig. 5A), while no amplicons were detected when testing DNA from milk of Serra da Estrela individuals (Fig. 5A). Additionally, amplification was also observed in DNA from mixture of milk from Crusade and Serra da Estrela breeds (Fig. 5B). In this way, we suggest these SCAR primers to be suitable for the identification of Crusade breed in the presence of Serra da Estrela milk and to be potentially useful for the detection of adulteration in Serra da Estrela cheese.

\section{Conclusions}

A RAPD method has been developed for efficient detection of an adulterant sheep breed in milk mixtures containing Serra da Estrela milk, and on this basis, SCAR markers have been designed, to allow breed identification in processed dairy foods. These methods may contribute to the set-up of a low-cost, reliable, fast and sensitive screening of milk origin in Serra da Estrela PDO cheese production. Additionally, it is, to the extent of our knowledge, the first time that RAPD-SCAR techniques have been applied to milk samples, establishing its applicability for quality control on the dairy industry. In this sense, the described methods will not only play an important role on the valorization of Serra da Estrela sheep breed and its related products, but may also be transferable for authentication of a wide range of dairy products, contributing to the maintenance of their high quality and to the economic development of the associated regional areas.

\section{Conflict of interest statement}

The authors declare that there are no known conflicts of interest associated with this publication.

\section{Acknowledgements}

The authors acknowledge Paulo Rogério Simões Figueiredo, Lda for supplying milk samples. This work was financially supported by the project "Valor Queijo" (CENTRO-07-0202-FEDER-030372) funded by FCT/MCTES (PIDDAC) and co-funded by "Fundo Europeu de Desenvolvimento Regional" (FEDER) through "COMPETE - Programa Operacional Factores de Competitividade" (POFC). This study was supported by the Portuguese Foundation for Science and Technology (FCT) under the scope of the Strategic Project of UID/BIO/04469/2013 unit and COMPETE 2020 (POCI-01-0145FEDER-006684) and the project RECI/BBB-EBI/0179/2012 (FCOMP-01-0124-FEDER-027462).

\section{Appendix A. Supplementary data}

Supplementary data associated with this article can be found, in the online version, at http://dx.doi.org/10.1016/j.foodchem.2016. 05.109.

\section{References}

Abdel-Rahman, S. M., \& Ahmed, M. M. M. (2007). Rapid and sensitive identification of buffalo's, cattle's and sheep's milk using species-specific PCR and PCR-RFLP techniques. Food Control, 18, 1246-1249.

Agrimonti, C., Pirondini, A., Marmiroli, M., \& Marmiroli, N. (2015). A quadruplex PCR (qxPCR) assay for adulteration in dairy products. Food Chemistry, 187, 58-64.

Blixt, Y., Knutsson, R., Borch, E., \& Rådström, P. (2003). Interlaboratory random amplified polymorphic DNA typing of Yersinia enterocolitica and $Y$. enterocolitica-like bacteria. International Journal of Food Microbiology, 83, 15-26.

Borràs, E., Ferré, J., Boqué, R., Mestres, M., Aceña, L., \& Busto, O. (2015). Data fusion methodologies for food and beverage authentication and quality assessment - A review. Analytica Chimica Acta, 891, 1-14.

Bottero, M. T., Civera, T., Nucera, D., Rosati, S., Sacchi, P., \& Turi, R. M. (2003). A multiplex polymerase chain reaction for the identification of cows', goats' and sheep's milk in dairy products. International Dairy Journal, 13, 277-282.

Chen, Y., Wang, Y., Ge, Y., \& Xu, B. (2005). Degradation of endogenous and exogenous genes of roundup-ready soybean during food processing. Journal of Agricultural and Food Chemistry, 53, 10239-10243.

Choy, Y. H., Oh, S. J., \& Kang, J. O. (2001). Application of RAPD methods in meat for beef breed identification. Asian-Australasian Journal of Animal Sciences, 14, 1655-1658.

Cirillo, A., Del Gaudio, S., Di Bernardo, G., Galano, G., Galderisi, U., \& Cipollaro, M. (2012). A new SCAR marker potentially useful to distinguish Italian cattle breeds. Food Chemistry, 130, 172-176.

Ferreira, I. M. P. L. V. O., Pinho, O., \& Sampaio, P. (2009). Volatile fraction of DOP "Castelo Branco" cheese: Influence of breed. Food Chemistry, 112, 1053-1059.

Fontanesi, L. (2010). Genetic authentication and traceability of food products of animal origin: New developments and perspectives. Italian Journal of Animal Science, 8, 9-18. 
Fontanesi, L., Beretti, F., Dall'Olio, S., Portolano, B., Matassino, D., \& Russo, V. (2011). A melanocortin 1 receptor (MC1R) gene polymorphism is useful for authentication of Massese sheep dairy products. Journal of Dairy Research, 78, $122-128$.

Ganopoulos, I., Sakaridis, I., Argiriou, A., Madesis, P., \& Tsaftaris, A. (2013). A nove closed-tube method based on high resolution melting (HRM) analysis for authenticity testing and quantitative detection in Greek PDO Feta cheese. Food Chemistry, 141, 835-840.

Ghazi, F., Benmechernene, Z., Kihal, M., \& Gurakan, G. C. (2013). The reproducibility of random amplified polymorphic DNA (RAPD) profiles of Streptococcus thermophilus strains with XD9, M13 and OPI-02 MOD primers. African Journal of Biotechnology, 12, 6245-6252.

Gonçalves, J., Pereira, F., Amorim, A., \& van Asch, B. (2012). New method for the simultaneous identification of cow, sheep, goat, and water buffalo in dairy products by analysis of short species-specific mitochondrial DNA targets. Journal of Agricultural and Food Chemistry, 60, 10480-10485.

Güçlü, F., Aldem, O. S., \& Güler, L. (2004). Differential identification of cattle Sarcocystis spp. by random amplified polymorphic DNA polymerase chain reaction (RAPD-PCR). Revue De Médecine Vétérinaire, 155, 440-444.

Kamal, M., \& Karoui, R. (2015). Analytical methods coupled with chemometric tools for determining the authenticity and detecting the adulteration of dairy products: A review. Trends in Food Science E Technology, 46, 27-48.

Khandka, D. K., Tuna, M., Tal, M., Nejidat, A., \& Golan-Goldhirsh, A. (1997). Variability in the pattern of random amplified polymorphic DNA. Electrophoresis, 18, 2852-2856.

Kumar, S., Kolte, A. P., Yadav, B. R., Kumar, S., Arora, A. L., \& Singh, V. K. (2008) Genetic variability among sheep breeds by random amplified polymorphic DNA-PCR. Indian Journal of Biotechnology, 7, 482-486.

Kumar, A., Kumar, R. R., Sharma, B. D., Gokulakrishnan, P., Mendiratta, S. K. \& Sharma, D. (2015). Identification of species origin of meat and meat products on the DNA basis: A review. Critical Reviews in Food Science and Nutrition, 55, $1340-1351$.

Lipkin, E., Shalom, A., Khatib, H., Soller, M., \& Friedmann, A. (1993). Milk as a source of deoxyribonucleic acid and as a substrate for the polymerase chain reaction. Journal of Dairy Science, 76, 2025-2032.

López-Calleja, I., Alonso, I. G., Fajardo, V., Rodríguez, M. A., Hernández, P. E., García, T., \& Martín, R. (2005). PCR detection of cows' milk in water buffalo milk and mozzarella cheese. International Dairy Journal, 15, 1122-1129.

López-Calleja, I., González, I., Fajardo, V., Martín, I., Hernández, P. E., García, T., \& Martín, R. (2007). Quantitative detection of goats' milk in sheep's milk by realtime PCR. Food Control, 18, 1466-1473.

Loutfi, A., Coradeschi, S., Mani, G. K., Shankar, P., \& Rayappan, J. B. B. (2015) Electronic noses for food quality: A review. Journal of Food Engineering, 144, $103-111$.

Perry, A. L., Worthington, T., Hilton, A. C., Lambert, P. A., Stirling, A. J., \& Elliott, T. S. (2003). Analysis of clinical isolates of Propionibacterium acnes by optimised RAPD. FEMS Microbiology Letters, 228, 51-55.

Qasim, M., Ahmad, H., Ghafoor, S., Afridi, S. G., Muhammad, I., \& Imtiaz, A. K. (2011) Estimation of genetic diversity in sheep (Ovis aries) using randomly amplified polymorphic DNA. International Journal of Animal and Veterinary Advances, 3 6-9.

Reis, P. J., \& Malcata, F. X. (2011). Ripening-related changes in Serra da Estrela cheese: A stereological study. Journal of Dairy Science, 94, 1223-1238.

Sardina, M. T., Tortorici, L., Mastrangelo, S., Di Gerlando, R., Tolone, M., \& Portolano, B. (2015). Application of microsatellite markers as potential tools for traceability of Girgentana goat breed dairy products. Food Research International, 74, 115-122.

Sentandreu, M. Á., \& Sentandreu, E. (2014). Authenticity of meat products: Tools against fraud. Food Research International, 60, 19-29. 